\title{
The Life-World and Its Multiple Realities: Alfred Schütz's Contribution to the Understanding of the Experience of Illness
}

\author{
Marie Santiago-Delefosse, María del Río Carral \\ Institute of Psychology, University of Lausanne, Lausanne, Switzerland \\ Email: marie.santiago@unil.ch, maria.delriocarral@unil.ch
}

Received 14 July 2015; accepted 8 August 2015; published 11 August 2015

Copyright (C) 2015 by authors and Scientific Research Publishing Inc.

This work is licensed under the Creative Commons Attribution International License (CC BY).

http://creativecommons.org/licenses/by/4.0/

(c) (i)

\section{Abstract}

Alfred Schütz original contribution to the social sciences refers to his analysis of the structure of the "life-world". This article aims to invigorate interest in the work of this author, little known in the field of health psychology. Key concepts of Schütz' approach will be presented in relation to their potential interest to the understanding of the experience of illness. In particular, we develop the main characteristics of the everyday life and its cognitive style, that is, its finite province of meaning. We propose to adopt this notion to define the experience of chronic or serious illness when the individual is confronted to the medical world. By articulating this analysis with literature in health psychology, we argue that Schütz's perspective brings useful insight to the field, namely because of its ability to study meaning constructions by overcoming the trap of solipsism by embracing intersubjectivity. The article concludes by outlining both, the limitations and research perspectives brought by this phenomenological analysis of the experiences of health and illness.

\section{Keywords}

Alfred Schütz, Health Psychology, Critical Psychology, Finite Provinces of Meaning, Qualitative Methods, Experience of Illness

\section{Introduction}

Alfred Schütz's (1899-1959) work can be situated within a phenomenological tradition in the Social Sciences 
and Humanities (Schütz, 1962, 1964, 1967; Schütz \& Luckmann, 1974; Schütz, 1987). His major original contribution to the field refers to his analysis of the structure of the "life-world". However, his thought is little acknowledged in psychology, despite the development of phenomenological perspectives in qualitative research initiated by Giorgi (2009) and Smith (2011) as well as, in somewhat lesser measure, the reference to MerleauPonty and Moustakas (Santiago-Delefosse \& Rouan, 2001).

More particularly in health psychology, numerous criticisms, namely stemming from qualitative approaches, have been addressed to the Biopsychosocial (BPS) model (Engel, 1977) and its cognitive-behavioural orientation. In this vein, critical trends have stated the merely rhetorical function of this model (Stam, 2000) by underlining its theoretical weaknesses to provide an adequate framework to study the psychological mechanisms underlying health and illness. Many authors have highlighted its reductionist character (Murray, 2014). First of all, the biological dimension overlooks the influence in health and illness of lived corporeality. Moreover, although the BPS model attempts to include the social axis - through social support, different stressors, etc.-it fails to integrate concrete living conditions concerning illness, that is, how these may shape, structure and organise psychological phenomena. Furthermore, the ways in which individuals actively engage in sense-making constructions in serious or chronic illness by mobilising both, corporeality and sociality, have received little attention from dominant trends in health psychology. The psychological dimension is most often assessed in these trends via the quantification of affects, feelings, emotions, thoughts, intentions, etc. Yet, as stated by Bruner (1993, 2003), we face the urge within our field to introduce "real" everyday life situations where "real" people feel, doubt, struggle, and evolve in specific historical, cultural and social contexts. In this vein, few conceptualisations in health psychology propose an adequate articulation of subjective adjustments at stake when confronted to chronic or serious illness (MacLaren, 1998; Santiago-Delefosse, 2014) and this despite a growing number of critical and qualitative studies. Some of them take into account subjective meaning attributed to the worlds of health and illness (Lyons \& Chamberlain, 2006; Murray, 2014; Sools, Murray, \& Westerhof, 2015). Others attempt to consider how structural, cultural and social determinants influence the daily lived experience of specific groups of patients and/or communities and how these may be empowered (Campbell, 2014; Campbell \& Cornish, 2014; Murray, 2004). Yet, the inherent complexity of the human condition calls for further advances in the field at theoretical and methodological levels in order to have a better comprehension of the lived experience of illness.

As supporters of "fundamental field research" (Santiago-Delefosse, 2012; del Rio Carral, 2014), we are concerned by the development of models that have the potential to dynamically embrace corporeality, sociality, and psychological dimensions. According to us, Schütz's thought represents an interesting perspective in this regard. His work, multi-layered and complex, has inspired a range of qualitative trends not only within phenomenology, but also within interactionist and ethnomethodological approaches in the social sciences and humanities including authors such as: Peter Berger, Aaron Cicourel, Harold Garfinkel, Thomas Luckmann, and others. Depending on the phenomenon under investigation, his work can also be linked to our discipline, and more precisely, to intentional psychology (Blin, 1995).

Schütz's approach aimed to confront social science methods with manifest everyday reality; his interest was strongly focused in the understanding of the "life-world" as subjectively experienced. In his view, individuals are not confined by their ego, but on the contrary, are always in interaction. Schütz refuses all reductionism, including the phenomenological, concerned by the identification of pure essences and a priori structures of the human mind. His thesis invests "interaction" and "subjectivity" with actual substance. Considered in these terms, Schütz's thought reveals a clear proximity with critical trends emerging in health psychology that reject abstract modelling and related methods. In fact, health psychology could benefit from Schütz's analysis of the life-world as composed of multiple realities, where each context has its own values, norms and demands. This article presents how can his contribution on the life-world enriches the study of the illness experience, namely through his definition of "finite provinces of meaning". First, certain definitions of his work will be presented. Without pretending to be exhaustive, we will develop concepts that are able to bring theoretical depth to our field. Then, we describe how such concepts can relate to the study of the lived experience of serious or chronic illness. Schütz's approach will be discussed in relationship to health psychology, namely by articulating our reflections with contemporary literature on the experience of illness. However, the limitations of our attempt to transfer Schütz's perspective to our field will be also briefly considered. We conclude by identifying useful aspects for future research in health psychology. 


\section{Schütz's Analysis of the Life-World: An Overview}

Faced with the sheer scope of Schütz's body of work, we must readily acknowledge the impossibility of summarizing it comprehensively in the course of the present article. This section will hence introduce the lineage of Schütz's thought, until now remained practically unacknowledged in health psychology.

Schütz shows that knowledge about the world (or "life-world") emerges from intersubjective construction and supposes multiple realities, beginning with the everyday life, and following others such as that of: dreams, arts, science, etc.

From birth, the everyday life-world provides human beings with "objects” that are already defined and conceptualised by society, as well as laden with cultural meaning. It is these objects that allow individuals to define both, the goals of their actions and useful means to complete these actions successfully. The life-world is organized through "cultural patterns of group life", defined by actions that have been performed and that can be observed from a third person perspective. In other words, these patterns, conveying rules, values, and demands, enable individuals to define methods by which to find their bearings in the natural and socio-cultural contexts. The objects that integrate historical surroundings lead individuals to construct "typifications" of others and the world, which serve to orient and situate themselves ("self-typification").

Intersubjectivity shall be considered as follows: the "other", although becoming possible only through "myself”, is neither "my” duplicate nor "my” likeness, but rather an alterity with which my "I" will relate and be in tension. It can be inferred that human beings perform their own internal attribution of meaning to the world through intersubjectivity. Hence, we can see how the perpetual process of attributing meaning in the life-world cannot consist solely in the solipsistic reduction to essences. It requires a process of further complexity, which cannot be understood outside its socio-cultural context, that is, its “cultural patterns of group life”.

Furthermore, the life-world and its interpretation occur in connection with biographical foundations, lived corporeality and affectivity. According to Schütz, we need to examine the meaning of actions for individuals as such meaning is experienced and modified in the course of those actions (as well as by reflexive considerations regarding that action). Meaning appears as the result of the interpretation of lived experiences across "cultural patterns of group life” or domains of life. It involves different types of attention or tensions of consciousness that become "finite provinces of meaning" to the individual.

In research, our aim becomes that of understanding human constructions of the life-world and knowledge about that world, as well as human modes of sharing with others. It is, after all, through action that human beings transform both the outer and their inner worlds. From this approach, we will pay particular attention to change experienced by the individual when moving from one reality to another.

Central in Schütz's thought, the feature of intersubjectivity will retain our attention, since it constitutes an attempt to integrate the contextualised social dimension into the phenomenological dimension of psychological mechanisms. Guided by key phenomenological concepts, Schütz produced ground-breaking developments to theorize human experience in multiple realities. According to us, the following two aspects of his thought can be highly relevant to research in health psychology. The first one is his definition of the everyday life-world. The second one regards the coexistence of "finite provinces of meaning" whose cognitive styles are partially in conflict given different "cultural patterns of group life”.

\subsection{The Everyday Life-World}

To Schütz, there is a reality that is fundamental to human beings. It is the everyday life-world, socially constructed and constantly changing, which allows individuals to situate themselves without needing to question values, meanings and orientations. This “taken for granted” reality is self-evident because individuals were born into it and that it existed long before them.

Living in the everyday-life world implies adopting a specific type of attention or cognitive style, characterised by the "natural attitude”, guided by common sense (Schütz \& Luckmann, 1974). Through this psychological attitude, individuals are able to engage into action. By doing this they transform their surrounding, interact, and communicate with others. At the same time, they are confronted to obstacles or constraints represented within this framework by the enactments of others (Schütz \& Luckmann, 1974). As outlined in Table 1 the everyday life-world construct provides the subject with not only a framework and a range of reference points, but also a set of unquestionable certainties. It can be defined through five dimensions:

1) the individual in situation, 
Table 1. Main characteristics of the everyday life-world (adapted from Schütz 1962, 1964, 1987).

The individual in situation

- Being born into a world that is already there, made of pre-existing meanings and culture, individuals are engaged into actions and interpretations that are made possible by an antecedent stock of acquired experiences that others transmit.

- The body occupies a central position and melds with the self, which holds the centre of the world; bodily activity (kinesthesis, sensorialities) transforms the world and connects each individual both, to the subjective duration of time (internal), and to shared spatial time (external).

- At each moment of everyday life, each individual exists in a biographically determined situation, whose history is constructed by the sedimentation of previous experiences and constitutes a unique and exclusively personal resource.

- These biographically determined situations position each individual within the world, in physical and temporal space, but also according to his/her own role and his/her moral and ideological position.

The world to the individual and the "texture of meaning"

Each individual constructs his/her own "world", however this is enabled through others, and more precisely, through the "texture of meaning” given to him/her, composed of: cultural objects, symbols, arts, institutions and, especially, language systems.

- The "texture of meaning" is therefore originated in "human actions" (one's own and those of others). It constitutes a cultural world or universe of significance whose interpretation allows individuals to situate themselves.

- The individual shares a community of space and time by participating in the development of others' lives through his/her actions.

The "I" and the "other"

- The I in its corporeality constitutes the centre of the world from which We, You and They can be distinguished. The We includes others who present systems of relevances deemed to be in conformity with that of the individual.

- Among the others, Schütz's distinguishes different groups:

a) contemporaries, with whom individuals share a community of time and space in the present cultural world. Individuals are closer to some than to others.

b) consociates are part of our contemporaries. This group refers to others with whom we are most often in physical proximity and with whom our relationships occur face to face; they can be either close individuals or strangers (with whom we find ourselves on the bus, for example);

c) predecessors are those on whom individuals cannot act, but whose past actions influence human actions in the present;

d) successors are those towards whom individuals can direct their actions by means of a certain degree of anticipation.

Typifications and meanings

- Experiences tend to sediment into "available knowledge" (that is, relatively circumscribed knowledge concerning the everyday life-world).

- A minute portion of this knowledge comes to the individual directly from personal experiences, while the greater part is acquired by way of socialisation.

- Organised by "types", this knowledge forms frameworks of potential experiences that individuals expect will be similar to those lived in the past. What they experience when they perceive an object is transferred onto other similar objects, from which individuals tend to retain only its belonging to a given typified framework. These types are essential to giving meaning to the everyday life-world.

- The individual does not analyse these "types" (the researcher does). He/she retains only certain aspects of typified objects. The individual is concerned with aspects that represent aspects of intentional interest. Schütz underlines that the object 'dog', for example, interests the dog's master not by what it has in common with other dogs, but by what the dog represents specifically for the master (its meaning), in this case: friend, companion, pet, etc.

- Typification and meaning are therefore connected, but the individual retains only those meanings that are useful to him for the everyday life-world (pragmatically).

- Typifications are transmitted through language; the shared knowledge of a given system of relevances becomes the "correct way of life" (what seems "natural" for members of a given group)

Intersubjectivity

- A separation of the I and the other appears impossible, given the shared character of language and culture.

- The latter are indispensable to the accumulation of available knowledge, to typification, and to the one truly important element of everyday life: the meaning of lived experience.

- The establishment of intersubjectivity implies, however, two cognitive functions:

a) the interchangeability of perspectives (structural socialisation of knowledge), which presumes similarities based on the self-model, based on the illusion that if others took the "I" perspective, they would understand what "I" am living (sharing of the same typicalities);

b) the idealisation of congruence, which allows for collaboration based on the assumption that the other and "I" interpret objects common to both in a manner that is sufficiently identical to achieve pragmatic goals.

- These two functions underpin the construction of "common prescriptions" allowing to manage "typical situations". This is "typified knowledge with a highly socialised structure".

- The typified models of others' behaviour become models that shape the actions of the self: they constitute the foundation of self-typification. 
2) the cultural world and the "texture of meaning",

3) the "I" and the "other",

4) typifications and meaning, and

5) intersubjectivity

On the basis of the characteristics presented above, Schütz's approach of the everyday life-world becomes possible through intersubjectivity as a cross-cutting issue. To him, each individual experiences this reality by integrating corporeality as the centre of his/her perspective of the world. Moreover, individuals mobilise "textures of meaning" that are originated in human actions, corresponding to language and culture within this "cultural pattern of group life". Typifications and meanings allow each individual to orient him/herself in the everyday life-world, even if he/she retains for his/her experience only those elements that are subjectively meaningful in this socio-cultural context.

Schütz's analysis thereby introduces the cultural and situational relativity of action, taking us beyond the solipsism of essences that are characteristic of the phenomenological approach. In his perspective, essences are shared through typified knowledge instead, at least in relation to common socio-cultural contexts and within cultural patterns of group life having internal systems of relevances.

\subsection{The Construction of Experience through Finite Provinces of Meaning}

In the course of everyday life, human beings harmonise the coexistence of seemingly disparate realities. To take one example, physicians live both, in the everyday life-world and in a medical world. Each one of these realities involves different constraints, demands and perspectives onto their consociates (particularly in the case of patients). By the same token, researchers also evolve in the everyday life-world, for instance when negotiating a job contract. Yet, when they elaborate research models, their relationships with contemporaries and consociates are very different. Hence, individuals evolve across multiple life realms.

How can we explain the coexistence of such different worlds and the individual's ability to pass between them without, in most instances, giving rise to significant contradictions? It is important to note that realities can indeed often come into conflict, for example when a physician, as an individual acting within the everyday life-world, must face a serious illness affecting a close and loved consociate: the distance required by the medical world of healing can therefore become more difficult to maintain given this particular situation. Established certainties that had been taken for granted can suddenly fall prey to doubt, unsettling lived realities. Such confrontation prompts a questioning of meanings that were formerly attributed to the world and of typifications that had until then held currency. In other words, the collision between worlds reveals the multiplicity of realities, that is, the groups of experiences or "cultural patterns of group life" composing the life-world. If this collision or "shock" can be experienced, it is because each one of these realities is different from one another in regard to their "finite province of meaning". Issued from the work of Husserl and that of James, this notion encompasses a set of experiences that have been made mutually compatible within a single "cognitive style" and that enable a specific tension of consciousness. The cognitive style gives experiences within one province of meaning an appearance of "unity" at phenomenological level. As long as lived experiences are integrated within one same cognitive style, the given province of meaning will be interpreted as reality in a self-evident way.

Beyond this multiplicity, the everyday life-world remains the "paramount reality", where the "natural attitude" is prevalent. But when affected by crisis or shock, individuals are led to burst through the limits of this particular finite province of meaning. By doing this, they shift their emphasis of reality to another province of meaning. For example, in the everyday life-world, pragmatic experience reinforces the apparent non-necessity of doubt: reality functions as it should, demonstrating the unity and congruity of the world and its validity. The experience of shock can be translated into a smooth alternation from one reality to another, but sometimes it can entail more important adjustments at subjective level.

Schütz delineates the cognitive style of finite provinces of meaning by means of six indicators: its form of tension of consciousness, its form of époché, its dominant form of spontaneity, its form of self-experience, its form of sociality, and its temporal perspective. The cognitive style can be assimilated to the subjective construction of experience, able to shape the individual's attitude towards a given reality.

Table 2 summarises the main characteristics of the dominant finite province of meaning that corresponds to the cognitive style of the everyday life-world.

The everyday life-world is defined by the "world of work", which dominates other forms of reality. Defined 
Table 2. The cognitive style of the "finite province of meaning” of the everyday life-world (adaptedfrom Schütz, 1962, 1964, 1967, 1987; see also Santiago-Delefosse, 2002).

\begin{tabular}{|c|c|c|}
\hline Indicators of the cognitive style & $\begin{array}{l}\text { Phenomenological categories } \\
\text { associated with the cognitive style }\end{array}$ & $\begin{array}{l}\text { Expression of the cognitive style in everyday } \\
\text { common sense reality }\end{array}$ \\
\hline Form of tension of consciousness & Being is a being-in-the-world & Full attention to everyday life and activity in the world \\
\hline Form of epoché & Being has no doubt about the world & $\begin{array}{l}\text { Suspension of doubt about the everyday reality, its } \\
\text { perception by the self and its validity }\end{array}$ \\
\hline Dominant form of spontaneity & Being is future projects and actions & $\begin{array}{l}\text { Work, action (based on a project and the intention to } \\
\text { advance a projected situation embodied in corporeality } \\
\text { aiming to modify the external world) }\end{array}$ \\
\hline Form of self-experience & Unified being-in-the-world & $\begin{array}{l}\text { The self involved in everyday activity and work, } \\
\text { perceived as the total self }\end{array}$ \\
\hline Form of sociality & Being-in-the-world present to relationships & $\begin{array}{l}\text { Common intersubjective world, (communication, } \\
\text { social activity, impression of sharing the same world as } \\
\text { consociates) }\end{array}$ \\
\hline Temporal perspective & $\begin{array}{l}\text { Present exists through its relationship with } \\
\text { past and future }\end{array}$ & $\begin{array}{l}\text { Standard time not present to consciousness; time } \\
\text { conceived as the temporal structure of the shared } \\
\text { intersubjective world (at the intersection of subjective } \\
\text { duration and cosmic time) }\end{array}$ \\
\hline
\end{tabular}

by physical objects including the body and its corporeality, this world of work allows human beings to engage into projects with the intent to transform the external world. It constitutes the archetype of all common experiences of reality. All other provinces of meaning are only modifications derived there from.

Based on this model, we can identify cognitive styles associated with other finite provinces of meaning. Previous research, for example, has focused on the cognitive style characteristic of the finite province of meaning of the world of serious and chronic illness. Elsewhere, attention has been accorded to the cognitive style of the finite province of meaning of the world of hypnosis, thus contributing to the debate pitting theories of consciousness change against those of social attribution (Santiago-Delefosse, 2012).

Schütz argues that the various realities experienced in the course of everyday life outside the "everyday world of work", such as the worlds of dreams, images, religious experience and scientific endeavour, possess their own finite province of meaning. According to him, research should hence focus on the study of the specific cognitive styles of these worlds.

In the everyday life-world, provinces of meaning do not communicate with one another. Since they are incompatible, passing from one to another involves a "leap", that is, the experience of shock. This leap is defined by a modification of the tension of consciousness, requiring an alteration in the individual's attention: a change in his/her vision of the world, his/her interests, etc.; in short, an existential modification.

Although social sciences and humanities research would gain much by studying each finite province of meaning, allowing for a better understanding of consciousness and changes in its tension, there remains however a crucial difficulty: it is that of language, which relates lived experience, yet belongs to the intersubjective world of communication and everyday work. Because of these features, it resists attempts to account for meanings that transcend its intrinsic premises.

\section{Understanding the Experience of Illness through the Notion of "Finite Provinces of Meaning"}

The analysis of the human experience through Schütz's approach of the everyday life-world seems particularly useful to the field of health psychology, and more particularly, to our understanding of the experience of illness. In the finite province of meaning of the everyday-life world, being in "good" health can be seen as an integrative part of the reality guided by common sense, allowing individuals to act in a self-evident way by taking for granted their corporeality and their relation to the world. Becoming ill can be consequently identified as the lived experience of a "leap" into another world, leading to a radical shock that confronts the individual to an unknown reality. This change entails the modification of the cognitive style of the "natural attitude".

Below, we present the categories defining the process of health as part of the everyday life-world on the one hand and, on the other, the transformations of this world during the process of chronic or serious illness. In fact, 
subjective adjustments do take place when being in "good” health; they are experienced as part of the natural attitude, which individuals tend to hold on to. Yet, their misrepresentation when moving to the world of illness seems to stress the perception of these adjustments, which suddenly become evident to the individual who experiences this shock. Table 3 proposes a definition of the world of illness through the lense of its compararison with the everyday life-world, characterised by "being healthy". Through the six indicators of the cognitive styles, we describe how the construction of the experience by the individual is dramatically modified by the world of illness, defined by the cultural pattern of group life of medical care. We have slightly changed the original sequence of the six indicators identified by Schütz in order to adapt the general notion of finite province of meaning to the experiences of health and illness in particular (Santiago-Delefosse, 2002).

Here above, the table shows how the phenomenological categories identified by Schütz can be useful to understand the experience of illness in comparison to the cognitive style of the everyday life-world. The first two indicators, "unified being-in-the-world" and "being-in-the-world present to relationships" refer more precisely to lived corporeality in chronic or serious illness. This refers to sudden presence of the body as the result of a division within the self, where it may be lived as a separate entity that seems foreign to the individual. Such corporeality simultaneoulsy introduces a division regarding the self towards contemporaries too, since they seem to grow appart from the individual's own corporeal experience. The expression in the province of meaning of illness of the two subsequent indicators- - "present exists through its relationship with past and future" and "being is a being-in-the-world"-regards the social dimension. We include in this dimension the result of the division between the self and his/her contemporaries; the experience of a time that is different from shared everyday temporality, and a modified attention induced by the physical withdrawal from the everyday life-world. Finally, the last two indicators, "being is future projects and actions" and "being has no doubt about the world" can be linked to the psychological dimension of the experience of chronic or serious illness. These last two indicators refer to meaning reconstructions and psychological adjustments undertaken by the individual. They can be namely reflected through the development of subjective theories of illness.

Table 3. The cognitive styles of the "finite provinces of meaning" of the everyday life and the world of illness (adapted from Schütz, 1962, 1964, 1967, 1987; see also Santiago-Delefosse, 2002).

\begin{tabular}{lll}
$\begin{array}{l}\text { Phenomenological } \\
\text { categories associated with } \\
\text { the cognitive style }\end{array}$ & $\begin{array}{l}\text { Their expression in everyday common } \\
\text { sense reality }\end{array}$ & Their transformation within the lived world of illness \\
\hline
\end{tabular}

Unified being-in-the-world

Being-in-the-world present to relationships

Present exists through its relationship with past and future

Being is a

being-in-the-world

Being is future projects and actions

Being has no doubt about the world
The individual is the agent of his/her own actions; he/she experiences the indivisibility of his/her own body

The individual's sociality and his relationship to others imply empathy and the feeling of being part of the same world

Shared temporality that is closely linked to the everyday life-world and that is therefore not present in the consciousness

The individual is aware and orients his/her attention to his/her surrounding world; he/she is activity in the world

Enacted, the individual accomplishes projects through his/her actions.

The individual accepts his/her world without questioning its appearance; he manages to isolate any concern in regard to death.
First division: Illness introduces a division within the individual as agent, who is suddenly separated from his/her own body, where the latter becomes an external, foreign and unfamiliar object.

Second division: Illness introduces a division within the individual's social world, where the latter is separated from the individual and his/her own body.

There is a modification of temporality through an exclusive focus on illness and its concrete consequences (frequent exams, time schedules for medication, hospitalisation, etc.) Time is experienced as chronic and frozen. External and internal times are unsychronised.

New attention required from the "new" world of medicine and healthcare. Modification of consciousness through medication along with tiredness and fatigue; withdrawal from his/her surrounding world.

The experience of illness alters the fulfillment of every project, frozen in a time that is now turned towards a new world surrounding the individual: that of healthcare.

Both, the experience of illness and the suffering body suddenly introduce the issue of death. Self-evidence towards the world and towards human relations is strongly shaken. The individual's perception of his/her own fragility and dealth become increasingly present. 
Analysing the crisis following the passage from the everyday life-world of health to the world of illness allows us to take into consideration the complexity of the illness experience. Literature in health psychology has broadly underlined the importance of patient compliance in their coping strategies when facing chronic or serious illness (ex. Jerome \& McAuley, 2013; Miller \& DiMatteo, 2015; Peel, Parry, Douglas, \& Lawton, 2005), Yet, Schütz's approach helps us to better understand diversified forms of adjustment from the subjective standpoint, by identifying how the individual is led to "deal with" his/her drama beyond compliance or noncompliance. Moreover, indicators described in Table 3 help us to embrace the subjective reconstruction of the world in relation to a given socio-cultural context. Indeed, this process remains closely linked to the meaning given to social encounters and to his/her interrogations on his/her own position within the world.

Based on the above, adjusting to the world, or more precisely readjusting to it, does not necessarily imply a compliant attitude following an external ethical framework which would advocate the adaptation to medical prescriptions as the "good way" to the being in the world. Instead, adjustments can take a variety of forms, which may, by the way, be little appreciated by the medical sector, such as treatment refusal. This is why we insist on the comprehensive perspective on the illness experience brought by Schütz's work. It focuses on the individual's reconstruction of the world, which does not presuppose any normative standards of what may be "right" or "wrong". At times, adjustments can be beneficial in the sense that they can open perspectives on personal projects allowing the individual for self-fulfilment. This could be the case when it is decided to give up IVF attempts. Sometimes, they can be detrimental to the individual, for instance in case of treatment refusal by an AIDS patient because of a determinant encounter with a guru. Be that as it may, the crisis or shock experienced with the onset of an illness leads to the perturbation of the unified everyday life-world. The leap to another reality calls for the reconstruction of the lived experience as a whole, which depends not only on the individual him/herself, but also on close relationships and the social environment. This subjective reorganisation implies:

- new interactions and encounters (namely with healthcare professionals);

- adjustments regarding close relationships and family;

- possibilities that the individual develops with regard to meaning attributed to illness.

Health psychology could benefit from comprehensive perspectives such as Schütz's approach to the study of the life-world because of the insight that it brings with its focus on the construction of subjective experience within concrete situations. The focus addressed in "classic" health psychology to the relations between the biological, the social and the psychological shifts in this approach to a more hermeneutical or relational approach. Schütz's work on finite provinces of meaning allows this by paying attention to:

- concrete interactions between the individual experiencing illness and caregiver(s);

- implementation of spaces of care;

- the lived experience of corporeality by the individual;

- meaning of support from the social environment and close relationships, motivating or not the reorganisation of a sense of unity within the individual;

- types of psychological support in regard to how the individual reconstructs his/her world by enabling his/her own point of view (including his/her own position towards existential issues on life and death).

It is interesting to note that intersubjectivity plays a central role in our analysis of the leap from the everyday life-world to the world of illness. Schütz's contribution to the understanding of this issue overcomes the tendency in psychological research, both quantitative and qualitative, to reduce the human experience either to variables or essences that are taken out of their original context, with the aim to reach generalisation (Ratner, 1997, 2002). The use of the six phenomenological indicators that define finite provinces of meaning allows us to integrate the subjective perception of the social anchorage and the situated nature of the experience of illness, which remains above all, unique to every individual. Schütz's analysis integrates, among others, corporeality and sociality in regard to lived changes, namely the separation experienced by the enacted individual towards his/her own body on the one hand, and his/her consociates on the other. In addition these entities are not considered as variables, but dependent on the meaning given by the individual in a relational way, given a specific context. Moreover, meaning constructions are enabled through language, which pre-exists the individual and therefore links him/her to a sociocultural context and community. This system of signs is fundamental not only because it underpins the typifications concerning the everyday life-world, but also, language empowers the individual to reconstruct psychologically his/her temporal, existential, corporeal and social experience of another reality that of illness and medical care. In sum, Schütz's approach on finite provinces of meaning allows us to 
work on how the individual co-constructs his lived experience, giving rise to subjective theories of illness, and therefore, acquire a better comprehension of this phenomenon.

\section{Discussion}

Schütz's perspective on the life-world embraces human experience as it takes place in a given reality, within a complex and multiple life-world. In this article, we show how this approach contributes in health psychology to analyse the experience of illness. In particular, his phenomenological focus on the everyday life-world through intersubjectivity prevents us from falling into the trap of solipsism. This focus brings theoretical depth to health psychology by envisaging the lived experience of health and illness without overlooking: intentionality, lived corporeality, and the roles of social interactions and their anchorage.

The urge for a relational perspective in psychology considering both, the self and the situation in human experience has been previously underlined by Ratner (1993, 1997). Kugelmann (2014) addressed this particular issue in the field of health psychology by intoducing a hermeneutical approach. Presenting similarities with Schütz's thought, Kugelmann defines health and illness as experiences or "dramas" that occur in our social world. To him, these dramas need hence to be studied in regard to concrete situations, with a specific form in space and time, but also culturally and socially (Kugelmann, 2014).

Still, Schütz's contribution to the field seems especially interesting to us because of its definition of multiple realities. In this regard, the notion of "finite provinces of meaning" enables us to take into consideration the phenomenological construction of health and illness by individuals given their specific "cognitive styles". At the same time, this approach goes without overlooking constraints that stem from the socio-cultural organisation of the world .The shock or crisis brought by the transition from the everyday life to another reality, in this case, to the world of illness, is provoked by a change in the individual's tension of consciouness. However, it is also influenced by the social environment through the passage to an unknown cultural pattern of group life, conveying specific demands, norms, rules, obstacles, etc. (Zittoun \& Gillespie, 2015). This experience puts into question subjective meaning constructions through change to a new world that calls for profound readjustements at corporeal, social and psychological levels. As Zittoun and Gillespie (2015) have argued, transformations involving the social environment demand the reorganization within the individual. In this sense, the province of meaning of the world of illness introduces new ways of experiencing the body, new modes of sociality, new temporalities, etc.

Stein (2008) suggests a similar standpoint in his analysis of personal narratives of sickness, by representing the illness experience as a transition to a different space and time that is completely new to the individual. By implication, the specificities of each "finite province of meaning" and the interactions between them (conflicts and adjustments) could be considered, in view of the accomplished action ("work") and its confrontation with others that are part of the life-world.

Still, when considering the reality of the everyday life-world of common sense and the reality of the world of illness we cannot state that one is "truer" than other. Immersed in one or the other of these worlds, or constantly moving between the two, the individual experiences reality under different frameworks of relevance. In either world, these frameworks account for only a part of overall reality. Since the different frameworks address different objects and are positioned differently in relation to their world, they cannot describe the same reality.

It is therefore crucial to bear in mind that researchers likely to integrate these elements in health psychology would therefore benefit from the study of the cognitive style(s) of the world(s) of individuals whose experience of illness is analysed. The cognitive styles corresponding to these worlds appear through their close intertwinements with the social dimension. In this regard, the latter is also constitutive of corporeality (Santiago-Delefosse, 2014), because embodiment is, too, intersubjectively mediated (Gallager \& Cole, 1995; Gallagher \& Zahavi, 2008).

\section{Conclusion}

In health psychology, chronic and serious illness can be analysed as experiences of the leap from the everyday life-world to another reality. This rupture of the "natural" attitude of being in the world involves the confrontation to medical surroundings introduced by illness. Schütz's phenomenological indicators of the cognitive styles can be thus used to characterise this experience, by allowing for a systematic analysis of the complex reorganisation in corporeality and sociality that results from this existential crisis. 
Schütz's approach has enabled us to introduce two main divisions in this reorganisation: the first one concerns the separation between the individual towards the living body. As it has been stated by Gallagher and Zahavi (2008), when action breaks down, the body becomes an object to the individual, standing in his/her way. Whereas the body often goes unnoticed within the province of meaning of the everyday life, a dualism is generated at corporeal level by the experience of illness. The second division is implied by change in the social world brought by medicine and healthcare, demanding the integration of new norms and constraints. This double split can be envisaged as the origin of different psychological adjustments which shape of new meaning constructions regarding among others: temporality, life projects, and the positioning of the self towards life and death. The attempt of transferring some of Schütz's concepts to our field must however be considered in the light of certain limitations. Indeed, his framework does succeed to introduce the socio-historical dimension to the understanding of the illness experience, namely through the notions of cognitive styles and their associated finite provinces of meaning. However, it may not seem to escape to a major limitation: that of idealising the full-awareness of the individual in his/her intentionality. Schütz admits that there are experiences that are automatic, yet to him, this implies that they are not subjectively meaningful in that they do not leave any memory "trace" (physiological reflexes or certain emotional states). However, it is possible to interrogate this assumption and to presume that there are some acts that are both embodied and meaningful, but that are beyond intentionality and language, especially when experiencing a crisis or shock (e.g. serious or chronic illness). From our perspective, this limitation confronts us to the complexity of capturing the human experience.

In addition, the analysis of the everyday life-world by Schütz fails to consider the development of psychological processes, whose role has nevertheless been underlined in other psychological approaches (Vygotsky, 1997, 1999). But different scenarios of the experience of illness could help us to conduct further analyses in this directionby focusing on the "leap" of one world to another, as to understand how individuals construct their experience in a reality that is still unknown to them. Hence, the approach developed by Schützsheds a complementary light to existing research in phenomenology focusing on the individual's embodied experience and emotions to study sense-making constructions (Sheets-Johnstone, 2009; Smith, 1996; Smith, 2011). In the future, research perspectives can be extended further in health psychology to move towards an embodied-social-psychological (ESP) model of the experience of illness (Santiago-Delefosse, 2014).

More generally, the framework underlying the multiple realities of the life-world can be used for its potential to improve the quality of research. At the heart of Schütz's work relies the premise of the gap between the everyday life-world, defined by enacting human beings—just like the researcher him/herself-and the scientific world, concerned by the identification of typifications to construct theories on the everyday reality. The researcher in health psychology, moving from one world to the other, must then ensure the adequacy of his/her interpretations, especially as his object under investigation concerns enacted individuals in a given sociocultural context (del Rio Carral \& Santiago-Delefosse, 2015). Future perspectives on methodological issues could be directed towards the analysis of the researchers' position who instead of trying to withdraw from the everyday world in their work, should integrate his values and attitudes to become aware of their influence (Danziger, 1994). Indeed, research could analyse how typifications that allow for the expression of knowledge in the everyday are constructed through cognitive styles while remaining grounded in everyday reality. Furthermore, researchers must be enabled with appropriate methods as to reveal the social and institutional structures operating in representative situations in order to grasp the cognitive styles involved in lived experiences in the world(s) of illness, as well as the subjective theories of individuals in those situations.

\section{References}

Blin, T. (1995). Phenomenology and Comprehensive Sociology. On Alfred Schütz. Paris: L’Harmattan.

Bruner, J. S. (1993). Acts of Meaning. Four Lectures on Mind and Culture. Cambridge, MA: Harvard University Press.

Bruner, J. S. (2003). Making Stories: Law, Literature, Life. Cambridge, MA: Harvard University Press.

Campbell, C. (2014). Community Mobilisation in the $21^{\text {st }}$ Century: Updating Our Theory of Social Change? Journal of Health Psychology, 19, 46-59. http://dx.doi.org/10.1177/1359105313500262

Campbell, C., \& Cornish, F. (2014). Reimagining Community Health Psychology: Maps, Journeys and New Terrains. Journal of Health Psychology, 19, 3-15. http://dx.doi.org/10.1177/1359105313500263

Danziger, K. (1994). Does the History of Psychology Have a Future? Theory and Psychology, 4, 467-484.

http://dx.doi.org/10.1177/0959354394044001 
del Rio Carral, M. (2014). Focusing on “A Day in the Life”: An Activity-Based Method for the Qualitative Analysis of Psychological Phenomena. Qualitative Research in Psychology, 11, 298-315.

http://dx.doi.org/10.1080/14780887.2014.902525

del Rio Carral, M., \& Santiago-Delefosse, M. (2015). Interpretation of Data in Psychology: A False Problem yet a True Issue. Philosophy Study, 5, 54-62. http://dx.doi.org/10.17265/2159-5313/2015.01.007

Engel, G. L. (1977). The Need for a New Medical Model: A Challenge for Biomedicine. Science, 196, 129-136. http://dx.doi.org/10.1126/science.847460

Gallagher, S., \& Cole, J. (1995). Body Schema and Body Image in a Differenced Subject. Journal of Mind and Behavior, 16, 369-390.

Gallagher, S., \& Zahavi, D. (2008). The Phenomenological Mind. New York: Routledge.

Giorgi, A. (2009). The Descriptive Phenomenological Method in Psychology. Pittsburgh, PA: Duquesne University Press.

Jerome, G. J., \& McAuley, E. (2013). Enrollment and Participation in a Pilot Walking Programme: The Role of Self-Efficacy. Journal of Health Psychology, 18, 236-244. http://dx.doi.org/10.1177/1359105311430869

Kugelmann, R. (2014). Health and Illness: A Hermeneutical Phenomenological Approach. In M. Murray (Ed.), Critical Health Psychology (pp. 55-70). Basingstoke: Palgrave Macmillan.

Lyons, A. C., \& Chamberlain, K. (2006). Health Psychology: A Critical Introduction. Cambridge: Cambridge University Press.

McLaren, N. (1998). A Critical Review of the Biopsychosocial Model. Australian and New Zealand Journal of Psychiatry, 32, 86-92. http://dx.doi.org/10.3109/00048679809062712

Miller, T. A., \& DiMatteo, M. R. (2015). Treatment Adherence/Compliance. The Encyclopedia of Clinical Psychology, 1-5. http://dx.doi.org/10.1002/9781118625392.wbecp167

Murray, M. (2004). Critical Health Psychology. Fasingstoke: Palgrave MacMillan.

Peel, E., Parry, O., Douglas, M., \& Lawton, J. (2005). Taking the Biscuit? A Discursive Approach to Managing Diet in Type 2 Diabetes. Journal of Health Psychology, 10, 779-791. http://dx.doi.org/10.1177/1359105305057313

Ratner, C. (1997). Cultural Psychology and Qualitative Methodology. New York: Plenum.

Ratner, C. (2002). Subjectivity and Objectivity in Qualitative Methodology. Forum Qualitative Social Research, 3. http://nbn-resolving.de/urn:nbn:de:0114-fqs0203160

Santiago-Delefosse, M. (2002). Psychologie de la santé: Perspectives qualitatives et cliniques [Health Psychology: Qualitative and Clinical Perspectives]. Liège: Pierre Mardaga Editeur.

Santiago-Delefosse, M. (2012). The Relevance of Vygotsky's Developmental Perspective to the Debate on Methodology in Psychological Science. Philosophy Study, 2, 515-526.

Santiago-Delefosse, M. (2014). The Need for an "Embodied-Societal-Psychological” (ESP) Model of Illness Experience. In M. Murray (Ed.), Critical Health Psychology (pp. 36-54). Basingstoke: Palgrave Macmillan.

Santiago-Delefosse, M., \& Rouan, G. (2001). Méthodesqualitatives en psychologie [Qualitative Methods in Psychology]. Paris: Dunod.

Schütz, A. (1962). The Problem of Social Reality: Collected Papers I. The Hague: Martinus Nijhoff.

Schütz, A. (1964). Studies in Social Theory: Collected Papers II. The Hague: Martinus Nijhoff.

Schütz, A. (1967). The Phenomenology of the Social World. Evanston, IL: Northwestern University Press.

Schütz, A. (1987). Le chercheuret le quotidien. Phénoménologie des sciences socials [The Researcher and the Everyday Life. Phenomenology of the Social Sciences]. Paris: Méridiens Klincksieck.

Schütz, A., \& Luckmann, T. (1974). The Structure of the Life World. Evanston, IL: Northwestern University Press.

Sheets-Johnstone, M. (2009). The Corporeal Turn: An Interdisciplinary Reader. Exeter: Imprint Academic.

Smith, J. A. (1996). Beyond the Divide between Cognition and Discourse: Using Interpretative Phenomenological Analysis in Health Psychology. Psychology \& Health, 11, 261-271. http://dx.doi.org/10.1080/08870449608400256

Smith, J. A. (2011). Evaluating the Contribution of Interpretative Phenomenological Analysis. Health Psychology Review, 5 , 9-27.

Sools, A. M., Murray, M., \& Westerhof, G. J. (2015). Narrative Health Psychology: Once More unto the Breach. Journal of Health Psychology, 20, 239-245. http://dx.doi.org/10.1177/1359105314566616

Stam, H. J. (2000). Theorizing Health and Illness: Functionalism, Subjectivity and Reflexivity. Journal of Health Psychology, 5, 273-284. http://dx.doi.org/10.1177/135910530000500309

Stein, M. (2008). The Lonely Patient: How We Experience Illness. New York: Harper Perennial. 
Vygotsky, L. S. (1997). The Collected Works of LS Vygotsky: Problems of the Theory and History of Psychology. New York: Plenum Press.

Vygotsky, L. S. (1999). The Historical Meaning of the Crisis in Psychology. Lausanne-Paris: Delachaux and Niestlé.

Zittoun, T., \& Gillespie, A. (2015). Transitions in the Life-Course: Learning from Alfred Schütz. In A. C. Joerchel, \& G. Benetka (Eds.), Biographical Ruptures and Their Repairs: Cultural Transitions in Development (pp. 147-157). Charlotte, NC: Information Age Publisher. 